\title{
Psychological Characteristics and Aesthetic Concerns of Male Patients Seeking Primary Rhinoplasty
}

\author{
Young Min Hah, Su Young Jung, Jeong Wook Kang, Jin Hyuk Huh, \\ Jin-Young Min, Sung Wan Kim, and Kun Hee Lee \\ Department of Otorhinolaryngology-Head and Neck Surgery, Kyung Hee University Hospital at Gangdong, Seoul, Korea
}

\section{코 성형술을 시행받는 남성 환자들의 심리적 특징 \\ 하영민 · 정수영 · 강정욱 · 허진혁 · 민진영 · 김성완 · 이건희 \\ 강동경희대학교병원 이비인후과학교실}

\author{
Received July 21, 2017 \\ Revised September 12, 2017 \\ Accepted September 23, 2017 \\ Address for correspondence \\ Kun Hee Lee, MD, PhD \\ Department of Otorhinolaryngology- \\ Head and Neck Surgery, \\ Kyung Hee University Hospital \\ at Gangdong, \\ 892 Dongnam-ro, Gangdong-gu, \\ Seoul 05278, Korea \\ Tel $+82-2-958-8474$ \\ Fax $+82-2-958-8470$ \\ E-mail nose $4 \mathrm{u} @$ gmail.com
}

Background and Objectives The demand for rhinoplasty has been high for both men and women over the years; recently, however, it is rapidly increasing for men as their interest in aesthetics has heightened. This study investigated the psychological characteristics of male patients who underwent rhinoplasty through questionnaire-guided consultation. In addition, we investigated the difference between patients and surgeons regarding their aesthetic concerns for rhinoplasty.

Subjects and Method Of the male patients who underwent rhinoplasty from January 2006 to December 2012, 124 patients who had completed the questionnaires were included. The questionnaire for rhinoplasty asked about the basic personality traits of patients, patients' complaints about their nose, reasons for receiving the operation and expectation for postoperative change.

Results Patients responded most to the item, "I have high expectations for the surgery" for the question regarding personality characteristics, followed by the response, "I am concerned about my health." Regarding questions about reasons for rhinoplasty, complaints about their dorsum were high; among these patients, they were most concerned about the appearance of the 'crooked nose' when viewed from the front. On the other hand, the concern for the 'poorly defined nasal tip' was not high, whereas it was defined as one of the problems mentioned by the surgeons.

Conclusion These results show differences regarding aesthetic concerns between the patients and the surgeon, especially regarding the nasal tip. It would be helpful for both patient and surgen to plan the surgery after careful consultation based on the questionnaire, accurate understanding of the patients' complaints and expectations to obtain satisfactory results for both. Korean J Otorhinolaryngol-Head Neck Surg 2018;61(5):252-7

\author{
서 론 \\ 코는 미용적인 측면으로는 얼굴의 한가운데 위치하며 얼 \\ This is an Open Access article distributed under the terms of the Creative Commons \\ Attribution Non-Commercial License (http://creativecommons.org/licenses/by-nc/4.0) \\ which permits unrestricted non-commercial use, distribution, and reproduction in any \\ medium, provided the original work is properly cited.
}

굴에서 가장 돌출되어 있는 구조로 한 개인의 외모나 인상을 평가하는 데 있어 상당히 중요한 역할을 한다. 또한 상부 호 흡기로서의 호흡 기능과 후각을 담당하는 생리적인 기관으 로 다른 장기와는 대체될 수 없는 중요한 의미를 지니고 있 다. 산업의 발달로 인한 산업재해나 외상에 의한 후천적인 외비 변형의 증가와 생활수준의 점진적인 향상에 따라 비정 
상적인 코로 인해 발생하는 코막힘이나 그 외의 다양한 증상 에 대한 인식 또한 증가하고 있다. 이에 따라 코의 기능적인 측면이나 미용적인 측면에 대한 관심이 증가하고 있으며, 코 로 인한 다양한 불편 사항을 교정하기 위한 방법 중의 하나 인 외비 성형에 대한 관심은 이미 남녀 모두에게서 높게 나 타나고 있다.1) 특히 최근 들어 남성들에서 사회 활동을 위한 하나의 도구적인 측면과 자기 개발을 위한 도구적인 측면의 하 나로 미용에 관한 관심이 증가하면서 남자들의 외비 성형에 대한 요구가 급격히 증가하고 있다.

미용적인 성형수술의 경우 훌륭한 결과를 위해서는 술자 의 술기만큼이나 적당한 동기와 기대치를 가진 환자를 선택 하는 것이 중요하며, 또한 환자의 요구와 의학적인 관점의 일 치 정도 역시 중요하므로 술 전 상담의 중요성이 그 어느 수술 에서보다 더 강조된다. ${ }^{2,3}$ 특히, 남성들의 성형의 경우 여성들 에 비해 아직은 상대적으로 덜 보편화된 분야인 만큼 남성 환자들이 수술을 결정하는 데 있어서나 수술을 시행받은 후 그에 대한 만족 여부를 평가하는 데 있어서 개인적인 성향이나 심리 상태가 미치는 영향력이 더욱 중시될 것으로 생각된다. 기 존의 여러 연구에서 외비 성형술을 시행받은 환자들의 전반적 인 심리에 대한 분석과 만족감에 대해 보고한 바 있으나 이 는 대부분 여자 환자들을 대상으로 진행된 연구들이다. ${ }^{4.5}$

이에 본 연구에서는 코 성형술을 시행받은 남자 환자들을 대상으로 하여 설문지를 통해 환자들이 수술을 결정하는 데 있어 작용한 심리적인 특징을 살펴보고자 하였으며, 더불어 집도의와 환자 사이의 심미적이고 기능적인 코 성형술의 필요 성에 대한 기준의 차이에 대해 알아보고자 하였다.

\section{대상 및 방법}

2006년 1월부터 2012년 12월까지 본원 이비인후과를 내원 하여 외비 성형술을 시행받은 남자 환자들 중 코 성형술 설문 지를 작성한 환자 124명을 대상으로 하였다(IRB No. 201804-006). 환자들 중 1) 이전에 코 수술을 시행받은 병력이 있 는 환자들, 2) 스스로 의사 결정을 할 수 없다고 판단된 환자 들, 3) 이전에 정신과 병력이 있는 환자들, 4) 연령이 18세 미만 인 환자들은 대상에서 제외하였다. 환자들은 모두 한 명의 숙 련된 집도의(K.H. Lee)에 의해서 코밖접근법(external rhinoplasty approach)을 이용한 외비 성형술을 시행받았으며, 수 술을 결정하기 전 외래를 통해 해당 집도의와 충분한 상담을 통해 수술의 시행 여부를 본인이 직접 결정하였다. 코 성형술 설문지는 수술을 시행하기 전날 환자가 직접 작성하도록 하 였으며, 설문지를 작성하기 전에 본 연구에 대해 충분한 설명 을 듣고 연구의 참여에 대해 자발적으로 동의한 환자들만을
대상으로 연구를 진행하였다.

본 연구에 사용된 설문지의 항목은 크게 네 가지로 분류 되며, 첫 번째 항목은 환자의 기본적인 성격 특성에 대한 질 문, 두 번째 항목은 외비 성형술을 결정하게 된 환자가 생각 하는 본인 코의 외형적인 문제점에 대한 질문, 세 번째 항목 은 수술을 통해 환자 본인이 기대하는 외비의 모양에 대한 질문, 마지막 항목은 수술 시 추가적으로 사용될 재료나 함께 성형 받고 싶은 신체 부위에 대한 질문으로 구성되어 있다.

환자들의 개인적인 성격적 특성에 관한 문항은 총 10 문항 이며, 환자 스스로 본인의 성격을 표현하는 항목들에 대해서 복수 응답도 가능하도록 하였다. 수술 후 기대하는 변화 정도, 수술 시 추가적으로 사용될 재료 및 함께 성형 받고 싶은 부 위에 대한 문항 역시 환자가 직접 응답하도록 하였다.

외비 성형술을 고려하게 되는 코의 대표적인 외형적 문제점 에 대해서는 총 9 가지 문항으로 구성된 설문지를 이용해 환자 본인 및 해당 집도의가 각각 해당하는 항목에 대해 응답하도 록 하였으며, 환자와 집도의가 서로의 응답 결과를 모르는 상 태에서 진행하였다. 필요할 경우 해당하는 모든 항목에 복수 응답도 가능하도록 하였다. 환자와 집도의 사이에서 동일한 설 문 문항에 대한 견해의 일치도를 분석하고자 Cohen's kappa 를 이용해 카파계수(coefficient of kappa)를 산출하였다.

\section{결 과}

Demographics of the patients (Table 1)

대상이 된 124명 환자들의 연령은 18 75세였으며, 평균 연령 은 26.9 \pm 11.5 세였다. 연령별 빈도는 20세 미만이 38명(30.7\%), 20 29세가 49명(39.5\%), 30 39세가 12명(16.9\%), 40 49세 9명 (7.3\%), 그리고 50세 이상이 7명(5.6\%)으로, 젊은 연령대에서

Table 1. Demographics of the patients

\begin{tabular}{lc}
\hline $\begin{array}{l}\text { Age (years), mean } \pm \text { SD } \\
\text { Range (years) }\end{array}$ & $\begin{array}{c}26.9 \pm 11.5 \\
18-75\end{array}$ \\
\hline $\begin{array}{l}\text { Age (years) } \\
-19\end{array}$ & Patient number (\%) \\
$20-29$ & $38(30.7)$ \\
$30-39$ & $49(39.5)$ \\
$40-49$ & $12(16.9)$ \\
$50-$ & $9(7.3)$ \\
Marital status & $7(5.6)$ \\
Single & \\
Married & $92(74.2)$ \\
History of nasal trauma & $32(25.8)$ \\
Yes & \\
No & $59(47.6)$ \\
\hline
\end{tabular}


높은 빈도를 보였다. 결혼 여부에 따라 나누었을 때 미혼자는 92명(74.2\%), 기혼자는 32명(25.8\%)으로 미혼자가 많았다. 코 의 외상력을 조사한 결과 외상을 받은 경험이 있는 자는 59 명(47.6\%), 특별한 외상력이 없는 경우가 65 명(52.4\%)으로 나 타났다.

\section{Patients' basic personality traits (Table 2)}

설문 결과 전체 124 명 중 34명(27.4\%)이 응답한 “수술 후 에 대한 기대가 아주 크다”가 가장 높은 응답률을 보인 문항 이었으며, "항상 건강이 염려된다"와 “무언가 잘못된 것을 알 면서도 하게 된다”가 각각 24명(19.4\%), 17명(13.7\%)으로 나타 났다. 그 뒤로 "여기 오기 전 여러 병원에 들렀다"와 "변덕이 심하다고 들은 적이 있다”가 각각 15 명(12.1\%), “수도꼭지나 가스레인지의 스위치가 잠겼는지 늘 걱정된다"와 "내가 하는 게 완벽하므로 남에게 일을 맡길 수 없다”가 각각 14명(11.3\%), "마음이 늘 불안하다"가 13 명(10.5\%)의 순으로 나타났다.

\section{Concerns of the patients and the surgeon (Table 3)}

“코의 어떤 면이 불만입니까?”라는 질문에 대한 환자들의 응 답을 조사한 결과 “코가 휘어졌다(휘어진 코: crooked nose)"

Table 2. Patients' basic personality traits

\begin{tabular}{lc}
\hline \multicolumn{1}{c}{ Personality traits } & $\begin{array}{c}\text { Patient } \\
\text { number (\%) }\end{array}$ \\
\hline 수술 후에 대한 기대가 아주 크다 & $34(27.4)$ \\
항상 건강이 염려된다 & $24(19.4)$ \\
무언가 잘못된 것을 알면서도 하게 된다 & $17(13.7)$ \\
여기 오기 전 여러 병원에 들렀다 & $15(12.1)$ \\
변덕이 심하다는 이야기를 들은 적이 있다 & $15(12.1)$ \\
수도꼭지나 가스레인지의 스위치가 잠겼는지 늘 걱정된다 & $14(11.3)$ \\
내가 하는 게 완벽하므로 남에게 일을 맡길 수 없다 & $14(11.3)$ \\
마음이 늘 불안하다 & $13(10.5)$ \\
가족들이 이 수술을 반대한다 & $3(2.4)$ \\
가족들 몰래 수술하고 싶다 & $3(2.4)$ \\
\hline
\end{tabular}

가 82명(66.1\%)으로 가장 많았고, "매부리코다(매부리코: hump nose)"와 “코가 낮다(낮은 코: low dorsum)"가 각각 38명 (30.6\%), 35명(28.2\%)으로 그 뒤를 이었다. "코끝이 뭉뚝하다 (뭉뚝한 코끝: poorly defined tip)"는 26명(20.9\%)으로 코끝 부분에 있어서는 "코끝이 처져 있다(아래로 처진 코끝: under projected tip)" 12명(9.7\%), "들창코다(위로 들린 코끝: over projected tip)" 6명(4.8\%)에 비해 높은 비율을 보였으나 휘어 진 코, 매부리코, 낮은 코와 같은 콧등 문제에 비해서는 낮게 나타났다.

집도의가 분석한 환자의 외형적 문제점에서는 매부리코가 62 명(50.0\%)으로 가장 많았고, 두 번째로는 휘어진 코가 55 명(44.4\%)으로 나타났다. 아래로 처진 코끝과 뭉뚝한 코끝이 각각 34명(27.4\%), 31명(25.0\%)으로 그 뒤를 이었다. 환자들 의 응답이 휘어진 코에 $66.1 \%$ 로 편향되어 있고 상위 세 항목 이 모두 콧등 문제였던 것에 비해, 집도의가 분석한 항목에서 는 콧등 문제와 더불어 코끝 문제도 높은 비율을 나타냈다.

각각의 설문 항목별로 구해진 카파계수는 모두 0.6보다 작 은 값을 보여 환자와 집도의 사이에서 의견이 일치하지 않는 경향을 보이는 것을 확인할 수 있었다 $(p<0.05)$ (Table 3$)$.

\section{Inconsistency between patient's concern and surgeon's} concern (Table 4)

외비의 문제점에 대한 응답에서 환자와 집도의 간의 불일 치 정도를 조사하였다. 실제로 문제가 있지만 환자는 불만을 제기하지 않았던 비율은 처진 코끝 $79.4 \%$, 들린 코끝 $75.0 \%$, "미간이 넓다(넓은 미간: too wide intercanthal distance)" $71.4 \%$ 의 순으로 조사되었다. 뭉뚝한 코끝은 $64.5 \%$ 로 코끝 부위 관련된 처진 코끝, 들린 코끝, 뭉뚝한 코끝 세 항목 모 두 높은 비율을 보였다. 콧등과 관련된 항목에서는 낮은 코, 매부리코, 휘어진 코가 각각 $46.7 \%, 51.6 \%, 18.2 \%$ 로 코끝 부위 에 비해 비교적 낮은 비율을 나타냈다.

실제 이상은 없었으나 환자가 불만을 호소한 비율은 휘어

Table 3. Concerns of the patients and the surgeon

\begin{tabular}{|c|c|c|c|c|c|}
\hline Patient's perspective & $\begin{array}{c}\text { Patient } \\
\text { number (\%) }\end{array}$ & Surgeon's perspective & $\begin{array}{c}\text { Patient } \\
\text { number (\%) }\end{array}$ & $\begin{array}{l}\text { Coefficient } \\
\text { of kappa }\end{array}$ & $p$-value \\
\hline Crooked nose & $82(66.1)$ & Crooked nose & $55(44.4)$ & 0.456 & 0.000 \\
\hline Hump nose & $38(30.6)$ & Hump nose & $62(50.0)$ & 0.554 & 0.000 \\
\hline Low dorsum & $35(28.2)$ & Low dorsum & $15(12.1)$ & 0.329 & 0.014 \\
\hline Poorly defined tip & $26(20.9)$ & Poorly defined tip & $31(25.0)$ & 0.341 & 0.011 \\
\hline Too wide in the middle third & $19(15.3)$ & Too wide in the middle third & $28(22.6)$ & 0.414 & 0.002 \\
\hline Too wide alar base & $17(13.7)$ & Too wide alar base & $14(11.3)$ & 0.371 & 0.005 \\
\hline Under projected tip & $12(9.7)$ & Under projected tip & $34(27.4)$ & 0.346 & 0.010 \\
\hline Over rotated tip & $6(4.8)$ & Over rotated tip & $8(6.5)$ & 0.288 & 0.030 \\
\hline Too wide ICD & $6(4.8)$ & Too wide ICD & $9(7.3)$ & 0.425 & 0.001 \\
\hline
\end{tabular}

ICD: intercanthal distance 
Psychological Characteristics of Male Patients Seeking Rhinoplasty I Hah YM, et al.

Table 4. Inconsistency of the results

\begin{tabular}{|c|c|c|c|c|}
\hline \multirow{2}{*}{ Type of deformity } & \multicolumn{2}{|c|}{ Surgeon's concern (-) } & \multicolumn{2}{|c|}{ Surgeon's concern (+) } \\
\hline & Patient's concern (-) & Patient's concern (+) & Patient's concern (-) & Patient's concern (+) \\
\hline Crooked nose & $32(46.4)$ & $37(53.6)$ & $10(18.2)$ & $45(81.8)$ \\
\hline Low dorsum & $82(75.2)$ & $27(24.8)$ & $7(46.7)$ & $8(53.3)$ \\
\hline Hump nose & $45(87.1)$ & $8(12.9)$ & $32(51.6)$ & $30(48.4)$ \\
\hline Poorly defined tip & $78(83.9)$ & $15(16.1)$ & $20(64.5)$ & $11(35.5)$ \\
\hline Under projected tip & $85(94.4)$ & $5(5.6)$ & $27(79.4)$ & $7(20.6)$ \\
\hline Over rotated tip & $115(95.8)$ & $5(4.2)$ & $3(75.0)$ & $1(25.0)$ \\
\hline Too wide alar base & $87(89.7)$ & $10(10.3)$ & $18(66.7)$ & $9(33.3)$ \\
\hline Too wide ICD & $113(96.6)$ & $4(3.4)$ & $5(71.4)$ & $2(28.6)$ \\
\hline Too wide in the middle third & $98(89.1)$ & $12(10.9)$ & $9(64.3)$ & $5(35.7)$ \\
\hline
\end{tabular}

ICD: intercanthal distance

Table 5. The desired nasal shape of patients

\begin{tabular}{lc}
\hline \multicolumn{1}{c}{ Desired shape } & No. of patients (\%) \\
\hline Straighten the nose & $69(55.6)$ \\
Ordinary shape & $45(36.3)$ \\
Augment nasal dorsum & $35(28.2)$ \\
Hump removal & $29(23.4)$ \\
Narrow the tip & $26(21.0)$ \\
Narrow alar base & $17(13.7)$ \\
Rotate tip & $3(2.4)$
\end{tabular}

진 코가 $53.6 \%$, 낮은 코가 $24.8 \%$ 의 순으로 나타났으며 뭉뚝 한 코끝이 $16.1 \%$, 매부리코가 $12.9 \%$ 로 그 뒤를 이었다.

\section{Desired nasal shape of patients (Table 5)}

설문지를 통해 환자들이 수술을 통해 기대하는 외비의 모 양에 대해 조사하였다. “어떻게 고치고 싶습니까?”라는 질문에 대한 응답으로 "코를 똑바로 하고 싶다(straighten the nose)" 를 원하는 환자는 69명(55.6\%)으로 가장 많았으며, 다음으로 “보통 모양의 코를 갖고 싶다(ordinary shape)"가 45명(36.3\%), “코를 높이고 싶다(augment nasal dorsum)”가 35명(28.2\%)의 순으로 나타났다. 이와 달리 “코폭을 좁히고 싶다(narrow alar base)"나 “코끝의 위치를 바로잡고 싶다(rotate tip)"의 경 우 각각 17 명(13.7\%)과 3명(2.4\%)으로 비교적 낮게 나타났다.

\section{고 찰}

외비 성형술을 시행함에 있어서 기능적인 면과 미적인 면 을 동시에 만족시키고 환자와 집도의 모두가 만족할 만한 좋 은 결과를 얻기 위해서는 다양한 요소들에 대한 포괄적인 고 려가 필요하다. 우선적으로 환자의 입장에서는 본인이 생각 하는 코에 대한 문제점과 그로 인한 수술의 필요성에 대한 강한 욕구와 수술 결과에 대한 기대치에 대해 충분한 고찰의
과정이 필요할 것이며, 집도의의 입장에서는 환자의 코의 문 제점에 대한 정확한 해부학적인 이해와 의학적인 분석, 또한 예상되는 수술의 결과와 환자의 기대치에 대한 적절한 조율 과정이 필요할 것이다. 특히 환자의 미용적인 욕구가 반영된 수술의 경우 일반적으로 수술 결과에 대한 환자들의 기대치 가 높은 경향을 보이는 것으로 알려져 있고, 다른 수술에 비 해 환자의 정신 심리 상태가 수술의 결과에 많은 영향을 미치 므로 환자의 육체적 상태뿐만 아니라 정신 심리적 상태를 잘 관찰하는 것이 필요하며, 따라서 수술 시행 전 충분한 상담과 면담을 통한 환자에 대한 면밀한 분석과 이를 바탕으로 하 여 적절한 의사-환자 간 신뢰를 형성하는 것이 중요하다. ${ }^{6,7)}$ 이미 여러 연구에서 외비 성형술을 받는 환자들의 심리적인 특성이나 술 후 결과에 영향을 미치는 정신 상태에 대한 연구 결과가 보고된 바 있으나 이는 대부분이 여성 환자들을 대상 으로 이루어진 연구였다. ${ }^{45)}$ 최근 들어 미용 수술 분야에서 남 성들의 욕구나 수요가 증가하는 추세를 보이고 있으나 아직 은 남성의 미용 수술이 여성에 비해 덜 보편화되어 있는 분야 인 만큼 수술을 시행받는 환자들에 대한 기본적인 특성이나 경향에 관한 뚜렷한 연구 결과는 없는 실정이다.

일반적으로 술 후 결과에 대해 문제를 제기하는 환자들의 특징으로 정신적으로 미성숙한 독신 남성이며, 수술 결과에 대한 기대가 너무 크고 자아도취적인 성격을 보이는 것으로 알려져 있으며, ${ }^{8)}$ Guyuron과 Bokhari ${ }^{7)}$ 및 Lee 등 ${ }^{3)}$ 의 보고에 서도 수술 결과에 대해서 남성 환자들이 더 높은 불만족을 보이는 것으로 보고하였다. 따라서 외비 성형술을 받는 남성 환자들에서의 수술 결과에 대한 만족도를 높이기 위한 방법 에 대한 연구의 중요성이 더욱 강조될 수밖에 없다.

본 연구에서는 환자들이 특별한 거부감 없이 평소 생각하 고 있던 코에 대한 불만 사항과 수술 결과에 대한 기대치, 그 리고 추가적으로 평소 본인의 성격적인 특성에 대해 자가 응 답이 가능하도록 고안된 설문지를 이용하여 환자들이 직접 응 
답하도록 하였다. 이러한 결과를 통해 외비 성형술을 시행받 는 남성 환자들의 전반적인 성격적 특성이나 미적인 관점의 특성을 알아보았다.

미용적인 성형수술을 받는 환자들의 경우 일반적인 인구에 비해 다양한 정신질환(mental disorder)을 동반하는 경우가 많 은 것으로 밝혀졌으며, ${ }^{910)}$ 특히 신체이형장애(body dysmorphic disorder), 자기애성 성격장애(narcissistic personality disorder), 그리고 연극성 성격장애(histrionic personality disorder)의 유병률이 일반 인구에 비해 5 25배 이상 높은 것으 로 보고하였다. ${ }^{11-13)}$ 본 연구 결과에서도 대상이 된 남자 환자 들은 평소 본인의 성격을 나타내는 문항들 중, 강박적인 성향 과 히스테릭한 성향을 의미하는 문항에서 다른 문항들에 비 해 높은 응답률을 보였다. 히스테릭한 성향을 보이는 사람들 의 경우 일반적으로 본인에 대한 관심이 높고 타인의 이목을 받는 것을 좋아하며 외모에 대한 관심 역시 높은 편이므로 ${ }^{14,15}$ 이러한 남자 환자들에서 일반적인 인구에 비해 외비 성형술 을 포함한 미용적인 수술을 받기 원하는 환자가 많은 것으로 생각된다. 또한 이러한 환자들의 경우 수술 결과에 대해서 비 현실적이며 실현 불가능할 정도의 높은 기대를 보이는 것으 로 알려져 있고, 따라서 수술 후 결과에 대한 만족도가 상당히 낮은 것으로 보고된 바 있으며, ${ }^{15)}$ 본 연구 대상자들에서도 유 사한 결과를 보이고 있다. 특히 환자들 중에서는 일부 본인 이 문제라고 생각했던 부분과 수술 후 원하는 코의 모양이 잘 일치하지 않는 경우도 있었으며, 일부는 수술 시행 여부 를 타인들이 확연히 알아챌 수 있을 정도로 인위적인 변화를 요하는 환자들도 있었다. 이는 아마도 항상 타인에게 주목 받 기를 원하는 히스테릭한 성향의 특성으로 인한 결과일 것으 로 생각된다.

설문 결과 강박적인 성향에 응답을 한 환자들 역시 높은 비율을 보였으며, 이는 기존에 알려진 신체이형장애(body dysmorphic disorder) 환자군에서 흔히 동반되는 정신질환 (mental disorder) 중의 하나이다. ${ }^{16,17)}$ 신체이형장애(body dysmorphic disorder)의 경우 특히 신체 부위 중 코에 대해 증 상을 보이는 경우가 많으며, 대부분 윤곽(contour)에 있어 "울 퉁불퉁한 코(bumpy nose)"를 호소하거나 모양(shape)과 관 련하여 휘어진 코를 호소하는 경우가 많은 것으로 보고된 바 있는데, ${ }^{12,14)}$ 본 연구에서 환자들이 불만족스럽게 느끼는 문 제점 중 휘어진 코와 낮은 코, 매부리코가 높은 비율을 보이 는 것은 이러한 연구에 부합되는 결과이다. 또한 강박적인 성 향의 경우 자기 관리가 철저하면서도 정해진 기준에 대한 융 통성이 없으며 문제시되는 일에 대해서는 반복 또는 집착하 는 경향이 있으므로, 스스로의 코의 모양에 대한 문제점을 인지하게 되면 그것에 대한 생각을 반복하게 되고 이로 인해
외비 성형술을 결심하게 되는 것으로 생각된다.

환자들이 생각하는 코의 외형적인 문제점과 집도의가 분 석한 문제점과의 차이를 살펴보면, 환자들은 뭉뚝한 코끝, 처 진 코끝, 들린 코끝과 같은 코끝 관련 항목에서 실제 문제가 있으나 이를 인지하지 못한 경우가 많았고, 이와 비교하면 매 부리코, 낮은 코, 휘어진 코 같은 콧등 관련 항목에서 문제를 인지하지 못한 비율은 상대적으로 낮은 것을 알 수 있다. 이 를 통해 환자와 집도의 사이에 심미적인 기준의 차이가 존재 함을 확인할 수 있었다. 다시 말해, 환자들의 경우 스스로 생 각하는 코의 문제점으로 전반적인 모양과 콧등 부위에 국한 된 문제점들을 호소하였던 반면, 집도의의 경우 콧등뿐만 아 니라 코끝 부위의 문제점 역시 골고루 지적하고 있었다. 일반 적으로 코끝 윤곽선(nasal tip contour)의 성공적인 조절 여부 가 외비 성형술의 전반적인 결과를 좌우하는 핵심 요소라고 알려져 있다. ${ }^{18)}$ 미적 기준에 부합하는 코끝 윤곽선을 만들기 위해서는 수술 전 코의 모양에 대한 충분한 분석과 이를 바 탕으로 적절한 술기를 시행하는 것이 필요하며, 따라서 술 전 코끝 윤곽선에 대한 분석은 환자와 집도의 모두에게서 만족 스러운 결과를 얻기 위해 필수적인 과정이다. 집도의의 경우 의학적인 지식을 바탕으로 하여 코의 기능적인 측면과 미용적 인 측면을 모두 고려하여 환자에게 가장 좋은 결과를 도출할 수 있는 방식을 선택하여 수술을 계획 및 시행하지만, 수술을 받는 환자들의 경우 대부분 이러한 분석 과정을 염두에 두지 않고 비전문적인 대중적 미의 기준으로만 생각을 하므로 환 자와 집도의 간의 관점 차이가 발생하는 것으로 생각된다.

일반적으로 외비 성형술을 받는 환자들의 경우 본인 코의 외형에 있어서 낮은 코, 휘어진 코에 대한 불만을 주로 호소 하는데, ${ }^{3}{ }^{3}$ 본 연구에서도 유사한 결과를 보고하였다. 이는 대 부분의 환자들이 표면적으로 드러나는 외비의 변형에 대해 서는 민감하게 반응하고 인식하지만 코끝의 위치나 변형, 융 기 등에 대한 세부적인 이상에 대해서는 쉽게 인식하지 못하 는 경향을 보이기 때문으로 생각된다.

콧등 관련 항목 간에 있어서도 매부리코나 낮은 코는 휘어 진 코에 비해 환자들이 문제를 인지하지 못한 비율이 더 높았 으며, 이는 매부리코나 낮은 코의 경우 정면보다는 측면(profile view)을 통해 관찰해야 정확히 진단할 수 있는데, 실생활 에서는 환자들이 자신의 측면(profile view)을 정확히 보기 힘 들기 때문인 것으로 여겨진다. 반면, 거울을 통해서도 정면에 서 쉽게 확인할 수 있는 휘어진 코는 실제 문제를 인지 못한 환자의 비율이 $18.2 \%$ 로 가장 낮은 항목이었고, 실제로 문제 가 없음에도 환자가 불만을 호소한 비율은 $53.6 \%$ 로 9 개 항 목 중 가장 높게 나타났다.

본 연구를 통해 환자가 생각하는 미적인 기준과 의사가 의 
학적으로 분석하는 미적인 기준이 다를 수 있음을 알 수 있 었다. 따라서 외비 성형술을 시행하기 전에 환자 개인별 설문 을 통해 환자가 생각하는 문제점과 원하는 수술 결과를 미 리 파악하고, 이러한 결과를 바탕으로 수술 전 환자와의 반 복적인 상담을 통해 환자와 집도의 간의 심미적인 기준의 차 이에 대해 충분히 설명한 후, 양자 간의 의견 조율 과정을 거 치는 것이 환자와 집도의 모두가 만족할 만한 결과를 얻는 데 도움이 될 것으로 생각된다.

대상이 된 남자 환자의 경우 대부분 수술에 대한 기대치가 상대적으로 높았고 건강에 대해 염려하는 성향을 보이는 것 을 알 수 있었다. 또한 대부분 환자들은 자신의 코의 콧등 부 위, 특히 휘어진 코에 국한된 불만이 많았으나 집도의의 의학 적인 관점에 따른 분석 결과 콧등 부위와 코끝 부위 모두에 서의 문제점을 지니는 환자들이 많았다. 이를 통해 집도의와 환자 사이에서 뚜렷한 심미적 기준의 차이를 확인할 수 있었 으며, 이러한 차이는 특히 코끝 부위에서 두드러지게 나타났 다. 이러한 미적 관점의 차이가 수술 후 결과에 영향을 미칠 수 있으므로, 수술 전 충분한 분석과 설문지를 바탕으로 한 면밀한 상담(questionnaire-guided consultation)을 통해 환 자의 기본적인 성격적 특성에 대한 분석과 함께 환자가 생각 하는 코에 대한 불만과 수술 결과에 대한 기대치를 정확히 파악하고 이를 바탕으로 수술 계획을 세우는 것이 환자 및 집도의 모두 만족할 만한 결과를 얻는 데 도움이 될 것으로 생각된다.

\section{REFERENCES}

1) Ishii LE, Tollefson TT, Basura GJ, Rosenfeld RM, Abramson PJ, Chaiet SR, et al. Clinical practice guideline: improving nasal form and function after rhinoplasty executive summary. Otolaryngol Head Neck Surg 2017;156(2):205-19.

2) Yu K, Kim A, Pearlman SJ. Functional and aesthetic concerns of patients seeking revision rhinoplasty. Arch Facial Plast Surg 2010; 12(5):291-7.

3) Lee BJ, Kim SY, Kim YJ. Clinical experiences of rhinoplasty with patients' assessment of the results. Korean J Otolaryngol-Head Neck Surg 1999;42(4):467-70.

4) Alsarraf R. Outcomes research in facial plastic surgery: a review and new directions. Aesthetic Plast Surg 2000;24(3):192-7.

5) Linn L, Goldman IB. Psychiatric observations concerning rhinoplasty. Psychosom Med 1949;11(5):307-14.

6) Sheard C, Jones NS, Quraishi MS, Herbert M. A prospective study of the psychological effects of rhinoplasty. Clin Otolaryngol Allied Sci 1996;21(3):232-6.

7) Guyuron B, Bokhari F. Patient satisfaction following rhinoplasty. Aesthetic Plast Surg 1996;20(2):153-7.

8) Tardy ME, Thomas JR, Brown RJ. Psychological assessment of surgical candidates. In: Tardy ME, Thomas JR, Brown RJ, editors. Facial Aesthetic Surgery. St Louis: Mosby;1995.

9) Ishigooka J, Iwao M, Suzuki M, Fukuyama Y, Murasaki M, Miura S. Demographic features of patients seeking cosmetic surgery. Psychiatry Clin Neurosci 1998;52(3):283-7.

10) Shridharani SM, Magarakis M, Manson PN, Rodriguez ED. Psychology of plastic and reconstructive surgery: a systematic clinical review. Plast Reconstr Surg 2010;126(6):2243-51.

11) Napoleon A. The presentation of personalities in plastic surgery. Ann Plast Surg 1993;31(3):193-208.

12) Wilson JB, Arpey CJ. Body dysmorphic disorder: suggestions for detection and treatment in a surgical dermatology practice. Dermatol Surg 2004;30(11):1391-9.

13) Sarwer DB, Wadden TA, Pertschuk MJ, Whitaker LA. Body image dissatisfaction and body dysmorphic disorder in 100 cosmetic surgery patients. Plast Reconstr Surg 1998;101(6):1644-9.

14) Malick F, Howard J, Koo J. Understanding the psychology of the cosmetic patients. Dermatol Ther 2008;21(1):47-53.

15) Ritvo EC, Melnick I, Marcus GR, Glick ID. Psychiatric conditions in cosmetic surgery patients. Facial Plast Surg 2006;22(3):194-7.

16) Veale D, Boocock A, Gournay K, Dryden W, Shah F, Willson R, et al. Body dysmorphic disorder. A survey of fifty cases. Br J Psychiatry 1996;169(2):196-201.

17) Phillips KA, McElroy SL, Keck PE Jr, Hudson JI, Pope HG Jr. A comparison of delusional and nondelusional body dysmorphic disorder in 100 cases. Psychopharmacol Bull 1994;30(2):179-86.

18) Toriumi DM. New concepts in nasal tip contouring. Arch Facial Plast Surg 2006;8(3):156-85. 